\title{
HOW TO ACHIEVE QUALITY EARLY CHILDHOOD EDUCATION FOR ALL: GOAL 4 OF THE UNITED NATIONS SUSTAINABLE DEVELOPMENT
}

\author{
Ali Kemal Tekin \\ University of South Australia
}

\begin{abstract}
Obtaining a quality education is essential to creating sustainable development. The overarching Goal 4 of the United Nations Sustainable Development Program (UNSDP) ensures that all girls and boys complete free primary and secondary schooling by 2030 . However, the early years represent the most important and vulnerable time period in the individual life-span and early education sets the fundamentals of achieving the overarching goal of SDG4. It is regarded as the golden time for ensuring strong foundations for life chances. Early Childhood Education (ECE) supports children's survival, growth, development and learning, including health, nutrition and hygiene, and cognitive, social, physical and emotional development $\mathrm{D}$ from birth to eight years old in formal, informal and non formal settings. Therefore, the United Nations (UN) set a sub goal under this notion exclusively for the early childhood education; By 2030, ensure that all girls and boys have access to quality early childhood development, care and preprimary education so that they are ready for primary education (SDG 4.2). Following the United Nations' notions, The dedicated member countries plan actions to achieve the necessities of the Goal 4 by 2030. These actions generally fall under eight categories: (1) Access and equity, (2) ECE governance, (3) Curriculum and pedagogy, (4) Teacher training, (5) Nutrition, (6) Family-School-Community partnerships, (7) Standards for learning environment, (8) Use of technology and digital materials. The presenter will provide information about these domains of improvement in order to meet the United Nations Sustainable Development Goal (SDG) 4.2 .
\end{abstract}


the tools required to develop innovative solutions to the world's greatest problems, eliminate hurdles in both individual and societal life. Therefore these fundamental education is critical to all global citizens for a better and productive life to live in peace and harmony. Despite these ambitions, there are several challenges in Governments efforts to fulfill the Goal 4.2. by 2030 . Thus, the road ahead especially for developing countries to ensure every child gets a strong start in life, is still long. A number of features undermine efforts of the Governments to expand coverage and improve quality of ECE. The Figure below shows the global gains in pre-primary enrollment.

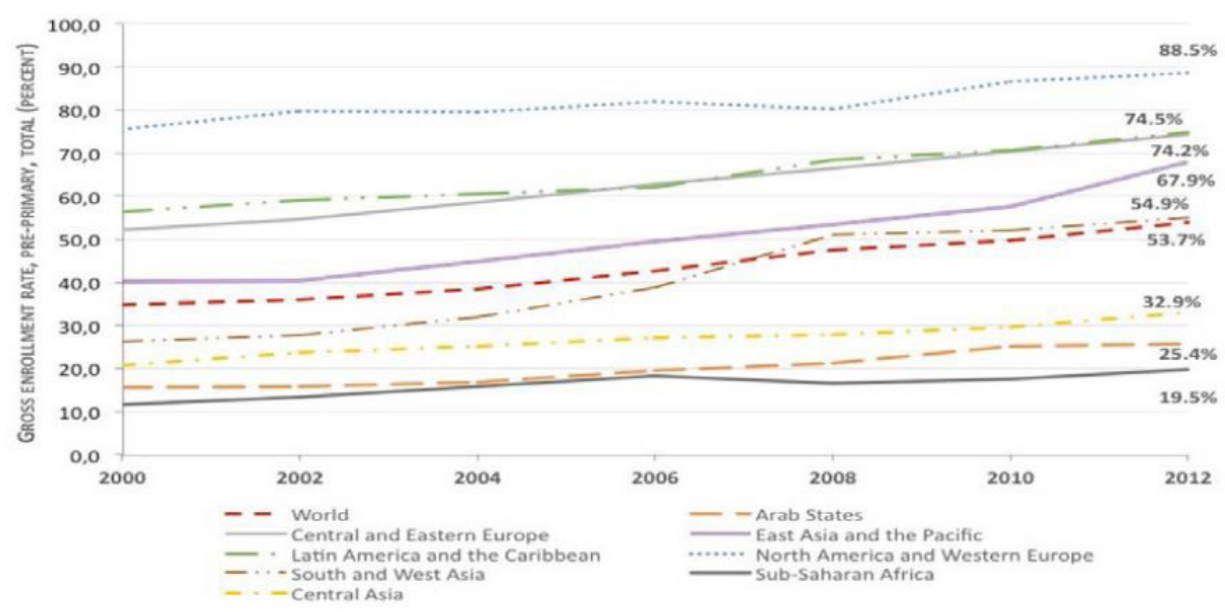

Figure 1. Global Gains in Pre-Primary Enrollement

Source: UNESCO Institute for Statistics, 2015

\section{Prognosing in Detail and Providing Recommendations}

There are eight main areas have been identified for improvement in developing countries follow up actions. These areas are:

(1) Access and equity

(2) ECE governance

(3) Curriculum and pedagogy

(4) Teacher training

(5) Nutrition

(6) Family-school-community partnerships

(7) Standards for learning environment
(8) Use of technology and digital materials

\section{(1) ACCESS AND EQUiTy}

Sustainable Development Goals 4.2. aims at ensuring at least one year of quality care and education before primary schooling to every child. The access to childcare and preschool is still extremely limited in developing countries, notably for children living in most deprived areas and households. Unregulated fees in private ECE provision along with lack of schemes in support of access of children from most disadvantaged socio-economic households, 
makes the ECE sector substantially inequitable in many developing countries (Appendix A).

A strategy to expand provision in order to meet the Sustainable Development Goal 4.2. should be designed, with specific programs could be developed in order to favor access to ECE for poor children, and children with special needs through alternative and cost-effective models (e.g. preparatory classes extended, vouchers schools, etc.). The strategy should be harmonized with programs to upgrade personnel skills and development of standards. The government's initiative, support, and intervention are of great significance to increase the access to ECE. The chance of healthy and successful increase in the access rate with quality is closed to none without the government's both policy and financial support.

\section{(2) ECE GovernanCE}

Despite examples of inter-sectoral cooperation, at policy level and daily practices, the coordination among line institutions and practitioners in ECE remains limited and mainly by personal efforts and contacts in many countries. This is mainly due to the inexistence of a common ECE vision and strategy, and the absence of technical teams devoted to ECE, and supervisors adequately trained, in sector ministries.

In order to develop a common understanding of ECE, establishing structures such as "Childhood Authority", to define, regulate, implement, monitor, and evaluate is of great significance. The authority should upgrade and harmonize existing strategic documents and sector strategies, as well. It is crucial, in this respect, that each governmental and non-governmental sector nominates ECE responsible/s to constitute a national ECE board under the "Childhood Authority" and must be fully integrated in the governance processes and structures. The authority should employ early childhood education specialists and other related professionals such as child protection officers and child nutritionists. Another necessity is to develop and introduce an "Early Childhood Education Act". This act will direct all stakeholders follow a national law in line with the international laws in ECE. It will also ensure and safeguard that all children receive their ECE according to a law and is under guarantees by the government.

\section{(3) Curriculum and pedagogy}

Countries need curriculum frameworks which will stimulate cognitive, non-cognitive and physical development, including health and nutrition, socio-emotional and moral and religious development of the child, and special education needs, from naissance to early grades of primary education, in accordance with the United Nations Convention for Child Rights. The curriculum framework should respond to the cultural specificities of the country and being age appropriate. In addition, standards and didactic material should be developed and/or updated according to the curriculum framework, in each ECE sector and provision type (private monolingual and bilingual, public preparatory classes, international, communitarian and other forms). This also implies the 
setting up a common framework for assessment learning achievements of children from naissance to early grades.

The curriculum must focus on the holistic development of the child, being age appropriate, and include aspects such as nutrition and health, socio-emotional development, protection, communication, use of technologies, along with moral and ethical development of the child. In addition, curriculum and pedagogical tools must consider (and adapt to) cultural specificities of the country (e.g. Islamic countries) and address special needs. In addition, a common framework for assessment (CFA) of progresses of children from early years to first grades of primary schooling should be set up. Yet, administrative data should be introduced properly and improved, in order to effectively map services, and their characteristics, in terms of infra- structures, personnel, costs, along with information about beneficiaries (gender, socio-economic status of families, and educational, nutritional and health outcomes). Data should be disaggregated at regional level, and by socio-economic status. This type of service can also be done by the "Childhood Authority".

\section{(4) TeACHER Training}

Many ECCE teachers do not meet the minimum requirements. Shortages of qualified teachers trained to national standards have implications for access and quality. Countries also have lower proportions of pre-primary teachers than primary teachers who are trained to national standards. The below figure shows Pre-service \& entry requirements for select low- and middle- income countries.

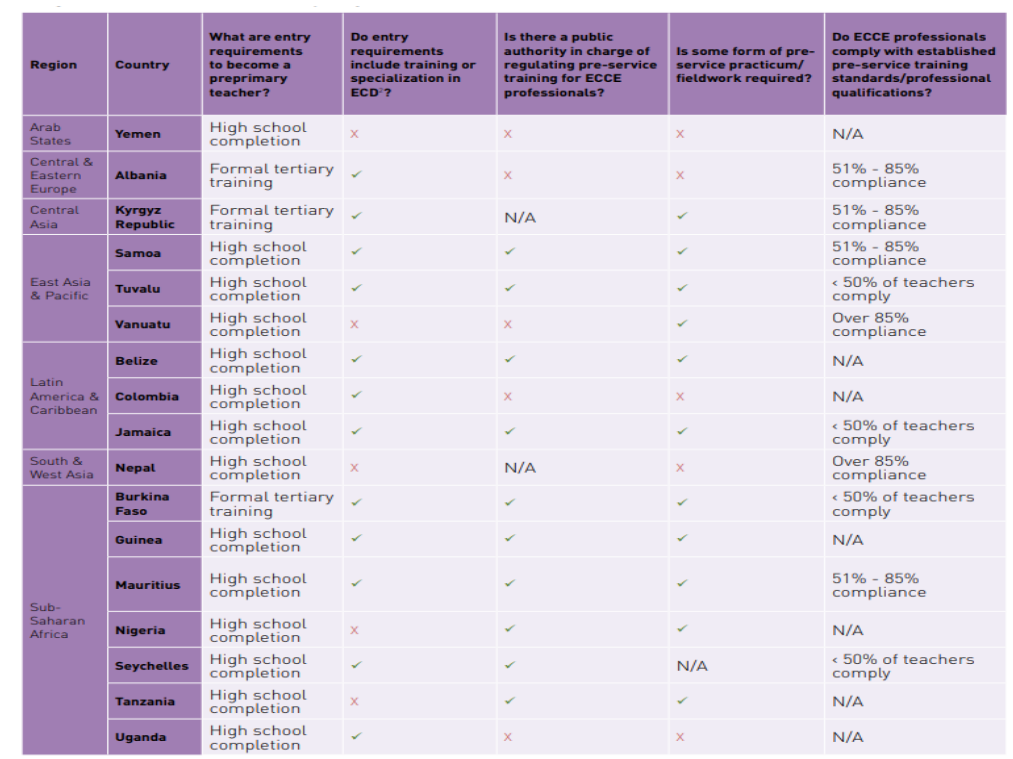

Figure 2. Pre-service \& Entry Requirements for Select Low-and Middle- Income Countries

Source: World Bank, SABER-ECD Database, Accessed August 2018 
Countries should give particular attention to professional development of ECE staff. Specifically, by developing a ECE program of training for in-set, preset training programs of teachers and personnel, in partnership with universities, to equip ECE personnel with skills to manage and organize the existing learning environment as well as acquire competences in the use of appropriate techniques and methods for childhood care and education. Standards for personnel's qualifications and working conditions should be established. Standards should be 'progressive' thus including minimum standards and a transitional period towards upgrading to full standards, in order to avoid to undermine efforts towards expansion of the sector. The below figure shows Proportion of primary and pre-primary teachers who are trained to national standards, 2013.

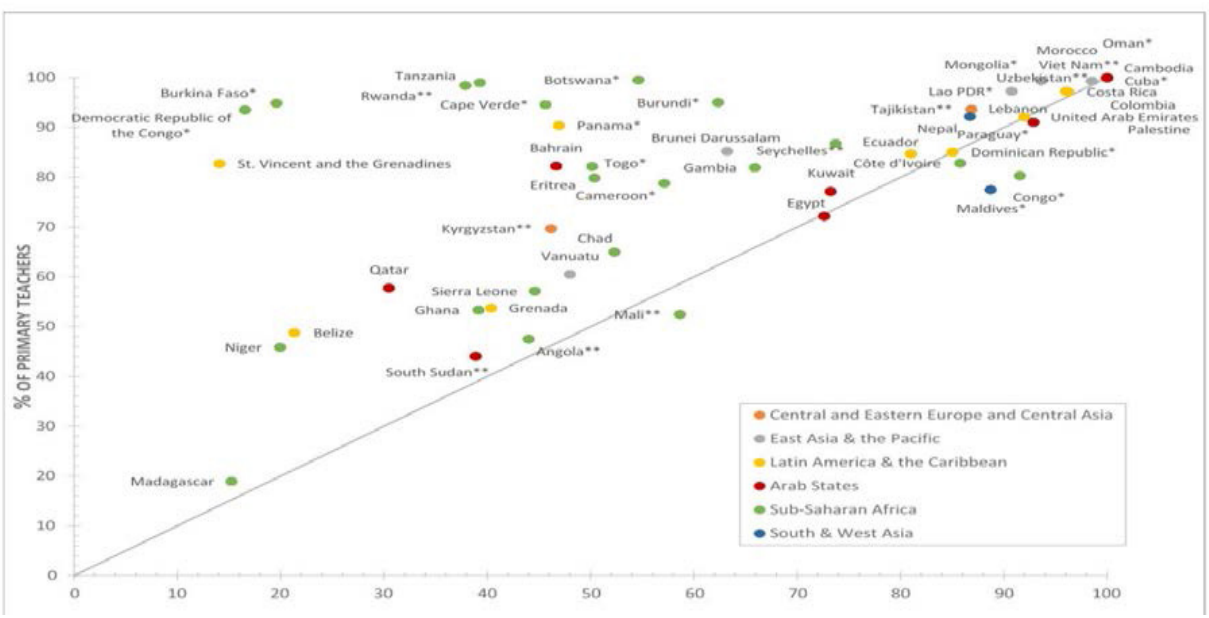

Figure 3. Proportion of Primary and Pre-Primary Teachers who are Trained to National Standards

Source: UNESCO Institute for Statistics, 2015

As the quality of teaching staff is the most important predictor of the quality ECE programs, the in-service teachers should not be left out. There needs to be compulsory professional development programs required from the private early childhood settings by the Government. These types of courses can be short term courses, for example, one semester during the weekends or evenings of the weekdays to make it convenient to attend for the in-service teachers and need to include the domains they have relatively weak knowledge and practice. In-service training requirements are generally weak and access to relevant professional development is limited in many countries. This type of training program will decrease the adverse and negative effects of the unqualified teachers on the child's development and learning. These training 
programs are needed to be in modules. Each module needs to target specific areas of the early childhood care and education. For instance, assessment and evaluation of the young child, dealing with the misbehaviors of the child, best practices and activities for different domains (cognitive, language, emotional, social, academic), setting up the physical environment, administering and managing the childhood setting, teaching in bilingual programs, nutrition and health, learning through play are needed to be delivered to the in-service teachers to outreach more children and receive the utmost positive outcomes from early education and care. Once the modules are completed, the teachers can receive certificates.

The burden of financial compensation of the instructors who are responsible to train the in-service teachers need to be on the both private and public sector, as well as the international organizations. Universities and training centers also can provide their facilities to make this type of training possible. The lack of such training program defects the overall quality of ECE. The below figure shows several good examples of Professional Development Programs.

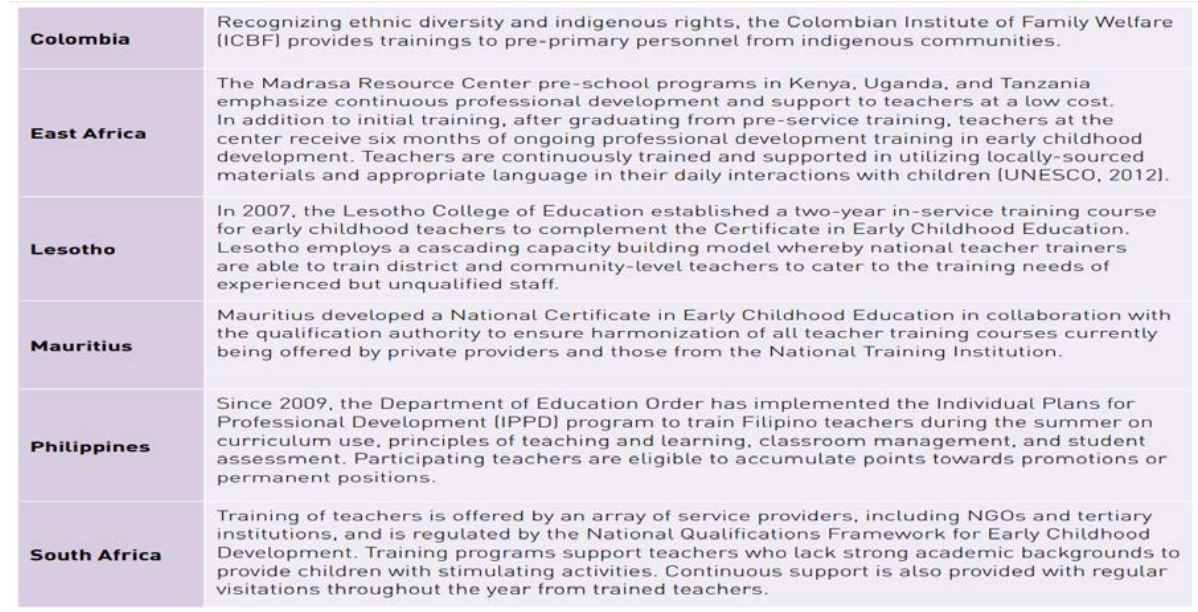

Figure 4. Model Professional Development Programs from Sample Countries Sources: Shaeffer, 2015 
Through the governmental and in- tion of early childhood teachers while ternational or national non-governmental organization efforts some countries have succeeded to have higher proporsome others failed. The below figure indicates the change in proportion of trained early childhood teachers.

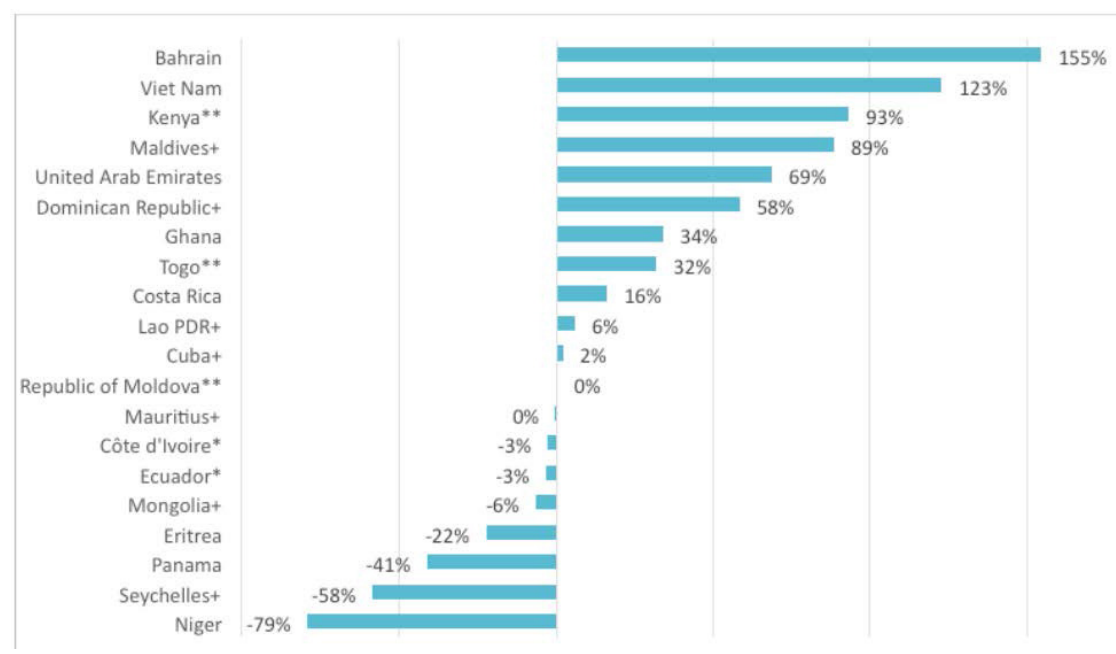

Figure 5. Change in Proportion of Trained Early Childhood Teachers

Source: UNESCO Institute for Statistics, 2015

\section{(5) Nutrition}

The children of developing countries such as Oman (See Appendix 2) and Indonesia (See Appendix 3) are suffering from several nutrition and health problems. There is not an harmonized education nutrition strategy for ECE, including standards and institutional arrangements between institutions, ensuring quality and efficacy of existing feeding programs in preschools and child care centers. Nutrition and health components are limitedly outlined in curriculum and are absent from staff's training.

A situation analysis is needed in order to assess existing feeding programs and services in terms of management, pedagogical inputs, effects on children's nutrition and health outcomes. The situation analysis should be harmonized with micro-nutrient surveys and children's health and nutrition screening system managed by $\mathrm{MOH}$. The analysis should be followed by a structured nutrition education strategy, establishing guidelines and standards for ECCE, along with institutional arrangements among ministries. Synergies will be established with the parallel project of training of trainers and teachers, in order to embed nutrition and health components in pedagogical tools and personnel's skills. 


\section{(6) FAMILY-SCHOOL-COMMUNITY PARTNERSHIPS}

Although the importance of a successful family-school-community partnership program is evident by numerous research studies and exist in abundance in the developed countries, there is scarcity of such programs implemented in developing countries and that is leaving the parents out of young children's educational life. Lacking of a systematic partnership between home and school that is crucial to be involved in any high stake nationwide ECE initiative. Finally, the positive experience of the awareness campaign should be reinforced by setting up a parental involvement program along with a parent involvement center as the parents (i.e. mother and father, grandparents, but also relatives, and care takers at home) are the most important figures in the child's life and they are the first educators of the child and major partners of sustainable educational development.

Family education programs should be conceptualized, starting from pilot the establishment of parent education center and. The parent involvement program similar to the other successful programs in western countries should be developed and parents are needed to be included from volunteering to decision making, from parenting to collaborating with the community. Parents (i.e. mother and father, as well as grandparents, relatives and care takers at home) are great source of education and any desired successful education occurs only if there are healthy school-home-and community partnerships. By parent ed- ucation, learning will not be limited to the school site, it will be continuous, and this consistency is the key for feeding the child's learning capacity during these golden years., and establish Parents Teachers' Associations (extended to $\mathrm{CBOs}$ ), in $\mathrm{KG}$, particularly in rural areas. The program must be tailored to reach diverse parents (parents in lower socio-economic status, single parents etc.). A parent involvement center at the "Childhood Authority" or the related ministry (e.g. Ministry of Education) can facilitate this kind of notion and function through the partnership with the experts from universities, specialized in parent involvement programs for young children.

\section{(7) NORMS AND STANDARDS FOR \\ LEARNING ENVIRONMENT}

The absence of complete well designed standards for physical infrastructures and learning supporting material in preschool and child care makes difficult for responsible ministries to supervise and monitor services, privately owned. In addition, "Childhood Authority" or Ministries should set up a program to support preschools to increase their standards, in all aspects, from age entrance, to learning material, nutrition and health, staff, and physical space regulating both public and private sector. For example, child-teacher ratio standard must be set and implemented in all ECE settings. The below figure depicts the pupil-teacher ratio in different regions of the world.

Moreover, capacity building of personnel on effective management 


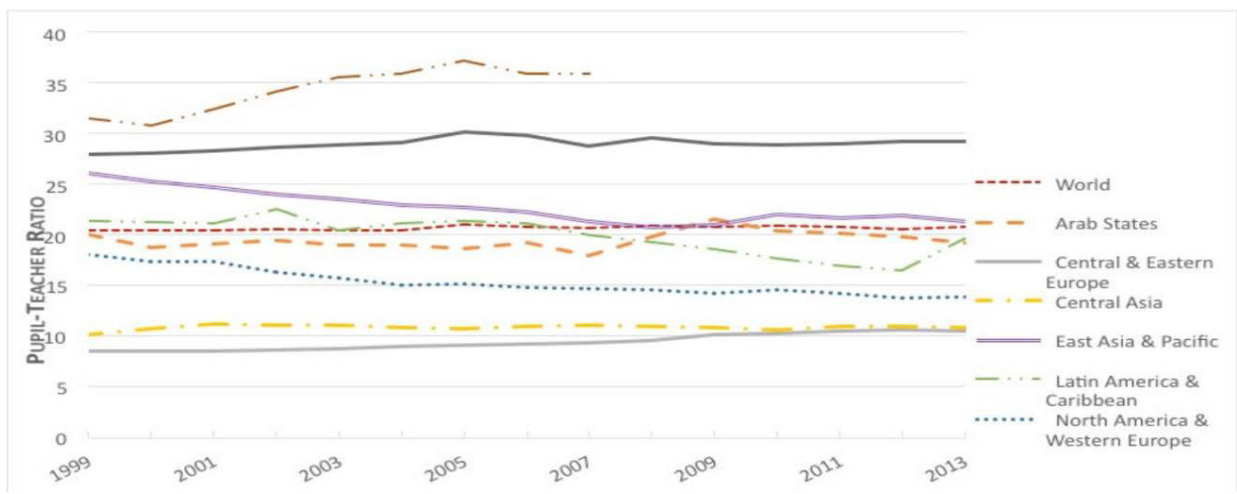

Figure 6. Pupil-Teacher Ratio in Different World Regions

Source: UNESCO Institute for Statistics, 2015

should be envisaged. Similarly to human resources, minimum standards and transitional period should be taken into account. The figure below illustrates the child-teacher ratio in the world regions. Consequently, the licensing procedures for the schools must these standards.

\section{(8) USE OF TECHNOLOGY AND DIGITAL MATERIALS}

Children of the modern era start to be engaged in the use of technology and employ digital materials at an early stage. Although some educators had doubt over the use of digital tools in young children's education, it has become a trend and an inescapable way of learning. Therefore, instead of avoiding the digital learning, there must be systemic outline of the ways of involving digital tools in early childhood education.

Teachers, parents, and children themselves are expected to use of technological tools such as internet-enabled mobile devices as they have become part of every individual's life and offer significant pedagogical opportunities. These technologies must be integrated into the early childhood classrooms as they are dynamic, social, visual, and tactile tools that facilitate immediate and responsive interactions between the knowledge and learner. Video clips, digital worksheets, interactive software programs, are examples of these materials. By using these materials in the classroom and having it as part of the curriculum, the children will not only develop their technological skills but also avoid the misusage of these tools. In order to employ the best practice, the teachers and parents must be trained about how to use, select, monitor, and evaluate the activities and tools of these digital means.

\section{REFERENCE}

Shaeffer, S. (2015). The promotion of decent work for early childhood education personnel: The professionalization of a neglected profession (Background paper for discussion at the 12 th session of the Committee of Experts on the Application of the Recommendations concerning 
Teaching Personnel [CEART]). World Bank SABER-ECD Database Geneva, Switzerland: ILO. (2018). Systems Approach for Bet-

UNESCO Institute for Statistics (2015). ter Education Results.Retrieved: Sustainable Development Goal 4 Indihttp:/ / saber.worldbank.org/incators.Retrieved: http://uis.unesdex.cfm

co.org/en/topic/sustainable-development-goal-4 